\title{
A MILITÂNCIA FEMINISTA NA WEB: O FUNCIONAMENTO DA ARGUMENTAÇÃO EM DISCURSOS SOBRE A VIOLÊNCIA NO PARTO
}

\author{
Aline Fernandes de Azevedo Bocchi* \\ Universidade de Franca \\ Franca, SP, Brasil
}

\begin{abstract}
Resumo: Neste estudo, são examinadas as categorias discursivas e argumentativas dos discursos feministas militantes, priorizando os metadiscursos léxico-semânticos que textualizam a violência médica contra a mulher durante o parto, ou seja, as formulações linguísticas que materializam o modo como as relações de poder atravessam e constituem esses discursos. Questionam-se, deste modo, as evidências ideologicamente construídas acerca das categorias de violência e militância por meio de uma abordagem discursiva que permite a análise e problematização de discursos designados como feministas e textualizados na materialidade significante digital. $O$ interesse está voltado, principalmente, para o funcionamento das designações e dos testemunhos em blogs militantes considerados lugares de interpretação e reformulação da experiência da violência no espaço digital.
\end{abstract}

Palavras-chave: Análise de discurso. Feminismo. Parto. Violência.

\section{TECENDO QUESTÕES SOBRE A MILITÂNCIA FEMINISTA}

Este artigo apresenta fragmentos de um estudo de pós-doutorado ${ }^{1}$ desenvolvido no Instituto de Estudos da Linguagem da Unicamp, com estágio realizado na Université Paris 13, e versa sobre o funcionamento argumentativo dos discursos contemporâneos de militância feminista que se formulam e circulam no ciberespaço, ou seja, analisa discursos produzidos especificamente no/para o digital, considerados tecnodiscursividades nativas da web (PAVEAU, 2013). Com fundamento em princípios da Análise de Discurso praticada a partir dos estudos de Michel Pêcheux (1990a [1969]; 2010 [1975]; 1990b [1982]), observamos os processos históricos de assujeitamento da mulher na formação social contemporânea, a partir de reflexões acerca da eficácia ideológica dos lugares de enunciação de sujeitos historicamente oprimidos. Nosso objetivo central está em trabalhar alguns discursos de militância que circulam nas redes digitais de sentidos, refletindo sobre seu potencial de resistência e práxis política, o qual reside na crítica aos processos de significação estabilizados na sociedade. Neste percurso, alguns autores foram fundamentais nas colocações acerca do discurso e dos processos enunciativos, quais sejam: Eni Orlandi

\footnotetext{
* Doutora em Linguística. Pós-Doutoranda CAPES/PNPD. E-mail: azevedo.aline@gmail.com.

${ }^{1}$ Pesquisa realizada com financiamento da Capes através do Programa Nacional de Pós-doutorado PNPD, com estágio no exterior financiado pela mesma Instituição, processo número 1362/2014-03, realizada no âmbito dos projetos de pesquisa "Mulheres em Discurso. Lugares de enunciação e processos de subjetivação", financiado pelo CNPq, processo 487140/2013-3, e do PHIM, Projeto História, Inconsciente e Materialidades; e do GTEDI - Grupo de Texto e Discurso: Representação, Sentido e Comunicação, nucleado na Universidade de Franca UNIFRAN.
} 
(1998, 2007a, 2007b, 2015), Mónica Zoppi-Fontana (1999, 2001), Eduardo Guimarães (1995), Onice Payer (2006), entre outros. Ainda, autores de outros campos auxiliam nas reflexões propostas, particularmente nomes que se situam nas Teorias feministas e Queer, quais sejam: Elsa Dorlin (2008), Judith Butler (2004 [1997]), entre outros; e historiadores, como Annette Wieviorka (2013 [1998]).

A análise procura mostrar como dizeres de militância se formulam e circulam nas redes digitais de sentidos, a partir de um corpus composto por recortes dos blogs "Cientista que virou mãe" e "Marie accouche là". Tais formulações nos mostram que, longe de se constituir como um campo de neutralidade, as palavras têm um potencial transformador, e que a luta política é antes de mais nada uma luta pelas palavras. Neste sentido, o apropriarse das palavras é uma forma de prática de militância que "joga" com o sentido, produz deslizamentos, inversões, metáforas ${ }^{2}$. Tendo em vista a narração como forma de exercício da escritura de si, do outro e do mundo, analisaremos as posições e os lugares discursivos formulados nesses discursos de militância, focalizando a atenção nas formas linguísticas presentes nessas postagens. É importante esclarecer que não se trata de uma análise sustentada por uma metodologia comparativa, embora a comparação compareça ao final como forma de aprofundar algumas reflexões, mas de um estudo que se ocupa de movimentos de interpretação que constroem diferentemente o parto e a maternidade. No que diz respeito à problemática do visual, para a análise de discurso, consideramos sua importância no modo de funcionamento do próprio digital, na relação entre diferentes materialidades significantes - o verbal, o imagético, o audiovisual, que se imbricam no digital. Essa relação constitutiva de discursos contemporâneos de cibermilitância foi problematizada em outros textos e não será explorada no âmbito deste artigo.

Inscrevemos, deste modo, gestos de descrição e interpretação ${ }^{3}$ voltados para: a) o funcionamento do dizer de um movimento político, formulado como discurso de denúncia que implica em convocar e informar, e que se constitui como uma prática discursiva forjada

\footnotetext{
${ }^{2}$ Da perspectiva da Análise de Discurso, o discurso é definido como efeito de sentidos entre interlocutores (PÊCHEUX, 1990a [1969]). Nele, as formas de existência histórica dos sujeitos e dos sentidos se materializam. Ao elaborar a noção de condições de produção na relação com os sujeitos e com as configurações sócio-históricas do aparecimento das discursividades, Michel Pêcheux (1990a [1969]) sugere que, no processo discursivo, é o efeito metafórico que permite a abertura do sentido, pois no deslizamento da cadeia significantes sentidos podem migrar, constituindo significações outras. "O processo discursivo é definido por Michel Pêcheux como o sistema de relações de substituição, paráfrases, sinonímias etc., que funcionam entre elementos linguísticos - significantes - em uma formação discursiva dada." (ORLANDI, 2010, p.17). O efeito metafórico, assim compreendido, não se reduz ao verbal, mas é parte do funcionamento da própria linguagem, pois é no deslizamento de um significante a outro que sentidos e sujeitos se constituem.

${ }^{3}$ Em Análise de Discurso, o gesto de interpretação é um conceito fundamental à análise. Ele se inscreve em uma prática de escrita particular, que consiste em situá-lo no movimento que vai da descrição à interpretação das sequências discursivas, acionando para tanto categorias teórico-analíticas próprias. Sua especificidade está em marcar uma diferença na compreensão teórica do conceito de sujeito, sustentada na crítica a concepções psicossociais e biológicas. Conceituado a partir de Pêcheux (1990a [1969]), que propõe uma compreensão do gesto como ato em nível simbólico, ou seja, como ato produzido em relação a um regime de sentido historicamente dado, o conceito de gesto de interpretação operacionaliza uma leitura discursiva que não dissimula o sujeito-analista de discurso, possibilitando assim uma leitura não subjetivista (PÊCHEUX, 2010 [1975]) da materialidade discursiva examinada. Isso porque a Análise de Discurso se sustenta em uma compreensão sócio-histórica e ideológica dos processos de constituição dos sujeitos e dos sentidos, dos quais o analista não pode escapar: enquanto sujeito, ele é determinado sócio-historicamente por meio de processos ideológicos. É a partir dessas determinações que o analista tece sua análise, em condições de produção acadêmico-científica específicas.
}

BOCCHI, Aline Fernandes de Azevedo. A militância feminista na Web: o funcionamento da argumentação em discursos sobre a violência no parto. Linguagem em (Dis)curso - LemD, Tubarão, SC, v. 16, n. 2, p. 309-328 maio/ago. 2016. 
pela militância digital. Tal prática de linguagem concerne à relação contraditória entre um modo de enunciação e a verdade enunciada, ou seja, diz respeito à relação do sujeito com o outro e com aquilo que ele tem como verdade; b) o funcionamento dos blogs como espaços de interpretação e reformulação de relatos de dor, violência e sofrimento, nos quais é possível entrever processos de reprodução / transformação da prática política no espaço digital.

Tendo em vista a internet como observatório de discursos considerado enquanto arquivo (PÊCHEUX, 1994 [1982]), ou seja, a partir de sua opacidade e sua equivocidade, interessa-nos examinar a materialidade específica de discursos de militância que se formulam e circulam no espaço digital, filiados a determinados campos de saber, no caso, à luta feminista por direitos das mulheres. Nestes discursos, há uma demanda estabelecida como reivindicação de direitos sobre o corpo na qual já se encontra uma interpretação posta acerca do parto e da maternidade. Na materialidade digital compreendida como espaço de significação (DIAS, 2012), consideramos a presença de coletivos políticos que defendem a causa do Movimento pelo Parto Humanizado em blogs e no Facebook, compostos por militantes que atuam como porta-vozes do movimento e por pessoas anônimas que se projetam discursivamente no ciberespaço através dos gestos performativos de "curtir", "compartilhar" e "comentar", ou seja, de dispositivos que promovem a articulação em rede (MITTMANN, 2011) de enunciados de denúncia e contrainformação. O comparecimento de blogs no Facebook indica que, neste processo de difusão de contrainformação, a articulação de diversos dispositivos integra os modos de circulação desses discursos digitais, constituindo a própria prática de militância. Devido à injunções próprias ao espaço de um artigo, versaremos mais detidamente sobre as formas de circulação desses discursos em uma ocasião mais oportuna. Interessa-nos, no entanto, reconhecer que os posts, constituídos na imbricação com blogs, entram no jogo da militância por esses gestos de "curtir", "compartilhar" e "comentar", que amplificam seus efeitos sociais, fazendo circular interpretações específicas sobre a mulher e a maternidade.

Nesta análise, em especial, abordamos o funcionamento da argumentação nesses discursos de militância, por meio da análise das marcas linguísticas que inscrevem neles posições-sujeito. O ponto de partida para a análise é o exame das designações formuladas pelas enunciadoras dos blogs "Cientista que virou mãe" e "Marie accouche là", ao falar de si e da prática militante, em seções dos blogs cujo objetivo é apresentar aquele que enuncia. Na sequência, examinamos os processos discursivos que constituem sentidos, pelas designações e adjetivações, para os nomes "mulher", "parto humanizado" e "violência obstétrica", objetivando verificar como tais categorias se apresentam tendo em vista o funcionamento da argumentação, nesses discursos militantes. Por último, verificamos como os testemunhos são mobilizados nestes funcionamentos argumentativos dos discursos militantes, procurando problematizar o jogo entre violência e censura e a proliferação de testemunhos nos "espaces numèriques" (PAVEAU, 2015).

\section{2 "MULHER", "MATERNIDADE" E "FEMININO" NOS DISCURSOS MILITANTES}

Neste estudo, consideramos, a partir da Análise de Discurso, que a construção discursiva do sujeito militante se dá por meio de processos ideológicos que se inscrevem na materialidade linguística das formulações. O gesto de análise, nas sequências 
discursivas que abordamos a seguir, procura mostrar como evidências ideologicamente construídas acerca dos conceitos de "mulher", "maternidade" e "feminino" se (re)produzem no funcionamento discursivo de pronomes e designações, sustentando um efeito de naturalização das categorias de gêneros em nossa formação social. Tanto os pronomes quanto as designações são compreendidos, desde a perspectiva discursiva, como marcas linguísticas que remetem à posições-sujeito neles inscritas, ou seja, à posições discursivas ideológicas inscritas no discurso como projeções de lugares sociais. Entendemos que o sujeito mantém relações contraditórias com os lugares sociais que ocupa em determinada sociedade. Esses lugares sociais são regidos pelo imaginário, isto é, eles não são os lugares empíricos (da mãe, da mulher, do pai, etc.), mas imagens que nossa sociedade constitui para eles. Assim, tendo em vista esses lugares de enunciação (ZOPPI-FONTANA, 2001), considerados a partir das relação de forças que constituem as condições de produção desses discursos, focalizamos as posições-sujeito de militância construídas por meio, principalmente, de pronomes e designações, em sua inexorável relação com a memória discursiva. Tal funcionamento constitui a argumentação dos discursos de militância analisados, permitindo uma reflexão fundamental para a compreensão das práticas contemporâneas de militância feminista. Sua crítica possibilita, então, compreender os avanços e limites da prática militante feminista, mapear suas fronteiras por meio da análise de seus discursos.

\section{Figura 1 - Blog "Cientista que virou mãe".}

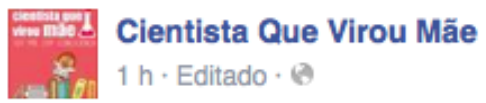

Pessoal, passando para lembrar: o blog Cientista Que Virou Mãe não aceita patrocínios de empresas. Não faz publieditoriais nem divulga grandes marcas, de grandes indústrias, que tenham mães, pais e cuidadores como público alvo.

Somos independentes, pessoal. Produzimos conteúdo para mães, pais e cuidadores gerado por mães e demais interessados na infância, na maternidade, em pautas que dizem respeito ao feminino, entre outras. Acreditamos que essa é uma forma de nos mantermos à margem da influência do grande mercado.

O blog vai passar por uma transformação a fim de se tornar autosustentável financeiramente e sabemos que isso já está circulando por aí (porque já está sendo divulgado via organizaçōes de negócios sociais). Mas essa transformação CONTINUA EXCLUINDO O PATROCÍNIO DAS GRANDES EMPRESAS E INDÚSTRIAS.

Acreditamos numa coisa muito séria: conteúdo para um público alvo precisa ser escolhido, apoiado e selecionado pelo público alvo.

Agradecemos por todo o oferecimento de patrocínios e convites para teste/divulgação e produtos oferecidos como brindes. Mas não aceitamos. Grata pela atenção.

(ت)

Curtir · Comentar · Compartilhar · $145 \square 7 \Leftrightarrow 1$

Fonte: Captura de tela 2015-06-16 à 20.51.04 (horário de Paris) 
Iniciamos o exame dos processos de produção de sentidos para "mulher", "maternidade" e "feminino" nos discursos digitais militantes com um recorte selecionado em uma postagem do blog "Cientista que virou mãe" no Facebook (Figura 1). Trata-se de um comunicado público que versa sobre uma "transformação" à qual o blog irá passar e cujo objetivo é torná-lo "autossustentável financeiramente". Grafado em letras maiúsculas, o enunciado "Mas essa transformação continua excluindo o patrocínio das grandes empresas e indústrias" procura reafirmar o caráter independente do blog: "Somos independentes, pessoal". Na postagem, há particularidades quanto às marcas linguísticas que, nesta interpretação, se sobressaem: abordamos, inicialmente, as formulações utilizadas para construir a posição discursiva daquele que fala; na sequência, ressaltamos a recorrência quanto ao emprego do nome "feminino" em posts do blog, discutindo sobre suas implicações político-ideológicas.

Observamos que há duas estratégias que se alternam na formulação da postagem. Na sequência inicial, "o blog" é formulado como sujeito (gramatical) de verbos de ação (aceitar, fazer e divulgar), em sua forma negativa ("o blog Cientista que virou mãe não aceita patrocínios". "Não faz publieditoriais nem divulga grandes marcas"). Mais à frente, o emprego dos pronomes desliza do "nós" para o "eu": "somos independentes"; "acreditamos que essa é uma forma de nos mantermos à margem da influência do mercado"; "acreditamos numa coisa muito séria..."; "Agradecemos...", "Mas não aceitamos". "Grata pela atenção". O interessante nesta formulação é a construção de um efeito de sentido de autonomia do blog, porém sem desvinculá-lo da blogueira Ligia Moreiras Sena, ativista, autora e "mãe da Clara", como ela mesma se descreve. O título do blog "Cientista que virou mãe" é ele próprio uma referência ao acontecimento que teria mudado a vida da autora: a maternidade. No espaço "a autora" (Figura 2), a construção da legitimidade daquela que escreve passa pela formação acadêmica de Lígia, salientando contudo sua experiência em relação à maternidade ("ser mãe de Clara é o título mais importante, pois foi o que realmente mudou minha vida e me ressignificou no mundo"). Neste espaço, a fotografia comparece inscrevendo, pelo corpo, uma posiçãosujeito que refere alguém no mundo, uma mulher entre outras: ela atesta uma existência, refere um sujeito particular. A autora explicita o que a motivou a idealizar o blog: "inspirada pelas mudanças que a maternidade promoveu em minha forma de ver o mundo e, principalmente, movida por uma grande contrariedade e insatisfação com relação a aspectos bastante nocivos a todos nós: a medicalização da vida e dos afetos, a patologização do normal, a institucionalização do corpo feminino e a biopolítica".

Essa última formulação é particularmente provocativa quanto ao modo com que a autora emprega o termo "feminino": trata-se de questionar a "institucionalização do corpo feminino". Tal referência se repete na postagem anterior (explicitada em Figura 1). Nela, observamos as especificações quanto ao conteúdo do blog: "Produzimos conteúdo para mães, pais e cuidadores gerado por mães e demais interessados na infância, na maternidade, em pautas que dizem respeito ao feminino, entre outras. Num exercício de paráfrase, nos perguntamos: por que feminino e não feminismo (ou "corpo da mulher", parafraseando a postagem acima)? Qual a implicação de não dizer-se feminista nestes espaços? O que tal declaração mostra em relação à posição enunciativa da autora e de seu engajamento na prática militante? Outro questionamento: haveria, nestas formulações, um indício de uma relação "natural" e "direta" entre a "mulher" e o "feminino"? 
Figura 2 - Espaço "A autora" do blog.

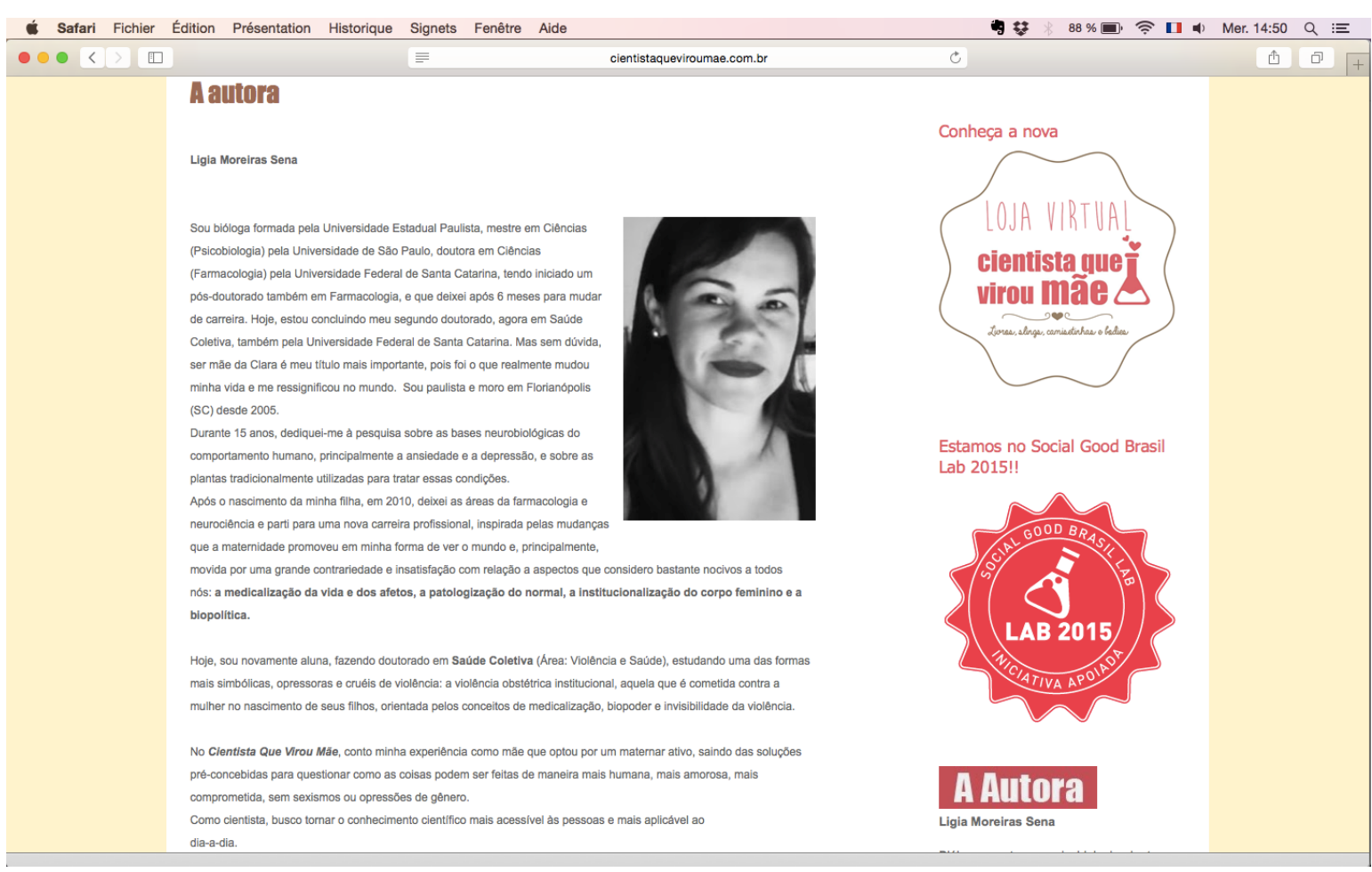

Fonte: Captura de tela 2015-08-19 à 14.50 .53 (horário de São Paulo)

Segundo Elsa Dorlin (2008), os saberes feministas podem ser considerados como memórias de combates, pois colocam em cena a reapropriação do corpo e da identidade das mulheres, através de um trabalho de conscientização que faz com que o destino de cada mulher, sua pretendida "condição feminina", seja reconhecida como experiência de opressão. Há uma postura ética e histórica que precisa ser assumida por quem se diz feminista, em sua prática de luta política. Historicamente, assumir um lugar de enunciação de defesa do feminino tem consequências concretas, pois a categoria do feminino é uma categoria criada pelo/no sistema de dominação patriarcal, uma categoria que historicamente naturaliza a mulher como constructo a partir de características essenciais próprias ao feminino. No caso do discurso da/sobre a maternidade, tal categoria viria a corroborar a naturalização da maternidade como construção do feminino.

Desta forma, o próximo recorte (Figura 3) parece contribuir com a compreensão desta opaca relação, por meio do funcionamento discursivo da designação. Segundo Guimarães (1995), os processos de designação são compostos por relações semânticas instáveis, produzidas pelo cruzamento de diferentes posições-sujeito, a partir dos quais instala-se um sentido, apagando outros sentidos possíveis, dizíveis. Nosso gesto de interpretação se volta, assim, para o nome adjetivado "divas parideiras", presente no título do texto veiculado no Facebook da "Cientista que virou mãe". 


\section{Figura 3 - Postagem do blog "Cientista que virou mãe".}

\section{Pots}

\section{Cientista Que Virou Mãe compartilhou a foto de Divas}

Parideiras.

$1 \mathrm{~h} \cdot \mathrm{\theta}$

Hora da aula: parto humanizado, cesárea desnecessária e parto normal real. É preciso informação. Urgentemente.

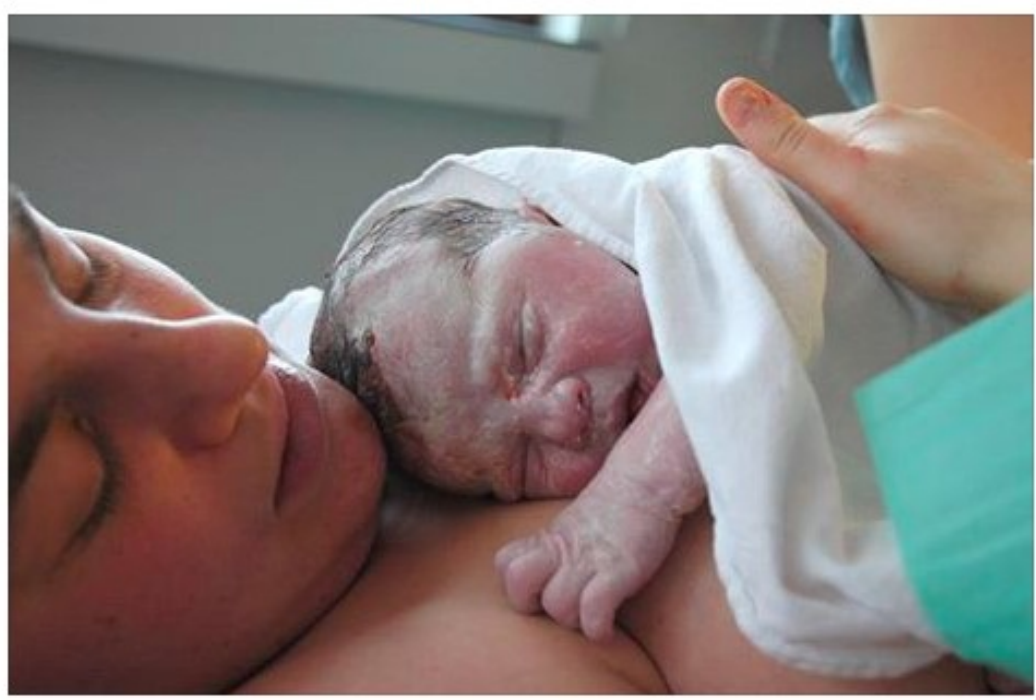

Divas Parideiras

Existe o parto humanizado. Existe a cesárea desnecessária, que tanto combatemos. E existe o parto normal real. Real porque é o que conseguimos, diante do cenário obstétrico brasileiro.

Muitas de nós tentaremos tudo para sermos respeitadas, e mesmo assim, ainda teremos o parto real, e năo o parto humanizado. No Brasil, o parto da maioria de nós năo vai ser lindo como nas fotos. Brigaremos muito. Levarão nossos fillhos pro berçário. Farão episiotomia na gente. Nos deixarão com as pernas pra cima. Farăo induçăo à toa. Nos deixarão sem comer e sem beber nada. Nos deixarão deitadas na maca, muitas vezes sem a assistência adequada. Proibirão a entrada da doula. Às vezes, até do companheiro (desrespeitando a lei). Isso é o \#partoreal no Brasil. Não é o parto que queremos, mas muitas vezes é o parto possível.

Às vezes, compartilhamos histórias aqui que não são partos humanizados. São partos reais, vindos de todos os rincões deste Brasil.

Vamos acolher estas mulheres, que lutaram e pariram. E conseguir parir, neste país, é coisa de muita luta. Vamos aplaudir sua coragem, apoiá-las. Nós sabemos que não é o parto ideal muitas vezes, mas é o parto possivel, para a maioria de nós. Abraços, divas!

Fonte: Captura de tela 2015-03-10 à 17.59.02 (horário de Paris)

Para Zoppi-Fontana (1999), é o nome que revela as fronteiras internas das formações discursivas, isto é, é ele que delimita o que é permitido dizer e o que é necessário silenciar. Segundo ela, tanto a designação quanto o objeto de referência são produzidos ao mesmo tempo, como efeitos de evidência pelos gestos de interpretação (ORLANDI, 2007b [1996]) que definem as diferentes posições-sujeito a partir das quais se enuncia. Isso quer dizer que as designações são efeitos dos gestos de interpretação, pois seu funcionamento consiste em construir discursivamente o referente, fixá-lo em relação a outras designações com as quais ele se encontra em relações parafrásticas no arquivo. Da mesma forma, os adjetivos, quando interpretados como determinantes linguísticos, operam impregnando o nome, "dando-lhe uma referência atual que o 
qualifica a ocupar uma posição lexicalmente identificada com um lugar referencial e a exercer funções semânticas e sintáticas" (INDURSKY, 1997, p.177). Entretanto, tal operação de determinação linguística não é suficiente para saturar o nome, ou seja, para estabilizar sua significação: é a determinação discursiva que irá fazê-lo, ao integrar sequências discursivas afetadas por determinadas formações discursivas.

Em qualquer discursividade, há processos de referenciação/designação que atuam de forma desigual, pois eles são efeitos do real histórico que, nas formulações, aparecem como contradições: as relações sociais são permeadas por embates dessemelhantes nos quais há, entretanto, uma posição dominante. Nosso percurso consiste, desta maneira, em examinar quais são os sentidos dominantes que se produzem discursivamente para designar a mulher.

Na designação "divas parideiras", a figura da diva, da musa, recebe um adjetivo que a determina, "parideira", nome derivado do verbo parir: dar à luz, partejar. Tal designação é formulada e circula de modo recorrente nas postagens que figuram no blog. O sentido de "divas parideiras", tal como considera a análise de discurso, não é dado ao modo de uma literalidade, do sentido um, mas é sobretudo construído no/pelo interdiscurso, através da identificação da posição-sujeito "militante" com a formação discursiva que a determina. É a ideologia que funciona, no processo discursivo, produzindo a evidência no nome, ou seja, a designação funciona, pelo interdiscurso, produzindo um efeito de pré-construído na identificação do objeto, apresentando-o como evidente, a partir de uma certa posiçãosujeito filiada a uma determinada memória. O sentido de mulher que se torna diva pelo parto é então construído, sustentado por um certo discurso sobre a maternidade. A passagem de "mulher" a "mãe" é, pois, a forma como o político vai constituir um certo lugar social para a mulher, que nesse discurso é explicitado como lugar de "empoderamento" pela maternidade. Entretanto, será que o mito da mulher pecadora merecedora da dor, conforme explicitado na escritura sagrada - "Farei com que, na gravidez, tenhas grandes sofrimentos; é com dor que hás de gerar filhos" (GÊNESIS 3-16) - tende a ser substituído, nos discursos em que figuram as diva parideira, pelo mito da super-mãe? Qual a natureza e o efeito social deste "empoderamento"? São questões que serão abordadas em uma outra oportunidade.

O mesmo processo de determinação/referenciação acontece na formulação "parto humanizado", designando uma determinada prática de nascimento a partir da produção de uma relação de evidência entre nome e referência. Devemos, conforme Pêcheux (2010 [1975]), considerar a separação entre o que é pensado antes, em outro lugar, e o que é construído no enunciado. Tais designações, assim formuladas, indicam que a posiçãosujeito "militante" se identifica com a "causa" do "parto humanizado", com seus ideais, construindo sua argumentação como forma de defendê-los. Na defesa de tais ideias, a informação é usada como "arma" de esclarecimento, como explicitado no enunciado que introduz a postagem: "Hora da aula: parto humanizado, cesárea desnecessária e parto normal real. É preciso informação. Urgentemente." O jogo da militância se constrói, desta forma, na relação entre convocar, através do mecanismo de interpelação que tais discursos praticam, informar e denunciar. É neste jogo que o discurso de militância faz “circular um discurso com pretensão revolucionária” (PÊCHEUX, 1990b [1982], p. 20), no discurso do mestre no qual há uma verdade a ser sustentada. Tais práticas militantes se assemelham à "posição pedagógica do militante-professor: 'escute-me! Eu vou revelar a verdade!'” (PÊCHEUX, 2011 [1979], p.74), sugerindo que divulgar e informar 
caminham pari passu com a "intenção" de denunciar e esclarecer. O gesto de formulação como lugar no qual a contradição se realiza nos mostra que o tornar público, o informar, entram no jogo de convencimento e persuasão que constituem o discurso de militância:

\begin{abstract}
Quanto mais se apresentam formas determinativas no dizer; quanto mais se prendem os sentidos na constituição de um sujeito determinado, menos fissuras se encontram no dizer; mais se produz o efeito de delimitação e fechamento, de saturação dos sentidos e, portanto, de adesão do sujeito enunciador àquilo que ele tem (enuncia) como verdade. (PAYER, 2006, p. 60)
\end{abstract}

Observa-se como a violência obstétrica, neste recorte, é formulada como "parto real":

\begin{abstract}
"No Brasil, o parto da maioria de nós não vai ser lindo como nas fotos. Brigaremos muito. Levarão nossos filhos pro berçário. Farão episiotomia na gente. Nos deixarão com as pernas pra cima. Farão indução à toa. Nos deixarão sem comer e sem beber nada. Nos deixarão deitadas na maca, muitas vezes sem a assistência adequada. Proibirão a entrada da doula. Às vezes, até do companheiro (desrespeitando a lei). Isso é \#partoreal no Brasil."
\end{abstract}

Segundo Orlandi (1998, p.76-77), duas noções estão na base do mecanismo de argumentação: a antecipação, sustentada pelo funcionamento das relações imaginárias; o esquecimento, noção relacionada ao interdiscurso, à exterioridade constitutiva do discursivo. Para ela, "argumentar é prever, tomado pelo jogo de imagens", isto é, a argumentação coloca em jogo um mecanismo no qual o interlocutor antecipa a imagem daquele para quem ele fala, e esse jogo é efeito de relações imaginárias. Orlandi considera que a espessura semântica dos objetos simbólicos é função do político, pois não há sentido que não tenha sido produzido em condições específicas, em uma relação com a exterioridade, com uma "direção histórico-social que se produz em relações imaginárias que derivam de um trabalho simbólico" (p. 75). O sujeito é, portanto, um lugar de significação historicamente constituído, ou seja, uma posição que se diferencia do sujeito empírico ou dos lugares objetivos da estrutura social típicos do sociologismo. Trata-se de lugares representados no discurso. Os mecanismos de projeção presentes em nossa sociedade estabelecem relações entre as situações objetivamente definíveis e as representações dessas relações nos discursos, ou seja, suas posições discursivas, conforme Pêcheux (1990a [1969]). Os lugares que os interlocutores atribuem uns aos outros, através desses mecanismos de antecipação, constituem as formações imaginárias, cuja natureza é discursiva: "não há apreensão perceptiva do referente, do outro e de si mesmo como condições pré-discursivas do discurso, supomos que a percepção é sempre atravessada pelo já ouvido e o já dito, através dos quais se constitui a substância das formações imaginárias" (PÊCHEUX, 1990a [1969], p. 85). Conforme Orlandi (1998, p.76):

\footnotetext{
${ }^{4}$ É importante explicitar que analisamos, neste recorte e no anterior, apenas a postagem, ou seja, não fazemos inferências sobre a forma como figuram seus comentários. Essa decisão se deu em razão do percurso analítico adotado, cuja proposta consiste no exame do funcionamento de pronomes e designações nesses discursos de militância. Entretanto, consideramos que os comentários são valiosos em uma abordagem dos modos de circulação da prática de cibermilitância, que consiste em "curtir", "comentar" e/ou "compartilhar" postagens, e deverão figurar em trabalhos futuros.
} 
Todo sujeito (orador) experimenta o lugar do ouvinte a partir de seu próprio lugar de orador, constituído pelo jogo das formações imaginárias (a imagem que faz de x, de si mesmo, do outro). Cada um "sabe" prever onde seu ouvinte o espera. Esta antecipação do que o outro vai pensar é constitutiva de todo discurso.

Então, neste jogo de antecipação, a posição-sujeito daquela que enuncia constrói discursivamente sua leitora como aquela que vivencia, como "todas as brasileiras", a violência obstétrica como realidade das condições de atendimento ao nascimento no Brasil. É uma posição que constrói o outro como reflexo, através do uso dos pronomes pessoais em primeira pessoa do plural, "nós", incluindo-se na realidade sobre o cenário obstétrico construída. Trata-se, assim, de denunciar e informar, esclarecer. Nesta relação, há um "tipo de vínculo ou de responsabilidade entre o sujeito que está em uma posição (imaginária) de enunciar o verdadeiro e o real sócio-histórico em que a enunciação se inscreve" (PAYER, 2006, p. 61)

No nível da formulação se situa a instância das intenções, que já se encontram determinadas e definidas por uma relação desigual e contraditória entre as formações discursivas. Isso quer dizer que as intenções são o produto de processos ideológicos aos quais o sujeito não tem acesso. "As filiações ideológicas já estão definidas e o jogo da argumentação não toca as posições dos sujeitos, ao contrário, deriva desse jogo" (ORLANDI, 1998, p. 78). O efeito da argumentação é, assim, o de produzir a evidência. Sob o efeito de sua ilusão subjetiva, o sujeito é afetado pela sua vontade de verdade. Ele convida o interlocutor a um modo de relação com o saber na qual há uma injunção ao engajamento político, ou seja, ele interpela o interlocutor à prática de militância, pelo modo com que produz o vínculo com seu leitor.

\section{3 "MARIE ACCOUCHE LA": UM CONTRAPONTO EXPLICITAMENTE FEMINISTA}

Há atualmente uma grande diversidade de blogs sobre parto e maternidade, especialmente no Brasil, o que sugere um amplo interesse pelo tema. Um deles é o da blogueira do Estadão Rita Lisauskas, cujo título é bastante sintomático: "Ser mãe é padecer na internet" e "denúncias" acerca de temas variados de interesse das "mulheres-mães-leitoras". Sua circulação está vinculada ao espaço do jornal $O$ Estadão, e isso certamente tem implicações sociais importantes em termos de produção de efeitos de sentido. O mesmo acontece com o blog de Marie-Hélène Lahaye, que circula sob o nome do conhecido Le Monde, conforme Figura 4.

O nome do blog "Marie accouche là" é bastante significativo, não apenas pela referência ao nome da autora, mas pelo uso do verbo "accoucher" (parir) como verbo de ação que implica um sujeito que o executa: Marie, Maria. No funcionamento dos nomes próprios, não há nenhuma univocidade em sua relação com o referente: "La règle est plutôt l'ambiguïté, la surdétermination, la polysignifiance" (GUILHAUMON, 2010). O nome próprio, habitado pela memória, é um espaço de trabalho da língua sobre o acontecimento. A escritura do nome próprio fazendo-o passar à ordem do nome comum

\footnotetext{
${ }^{5}$ Disponível em: <http://vida-estilo.estadao.com.br/blogs/ser-mae/> . Acesso em 01 dez. 2015.
} 
sugere uma passagem do singular ao universal. Ele funciona, neste recorte, pela contradição: refere a subjetividade da autora e, ao mesmo tempo, produz um efeito de universalidade a partir de um processo de identificação com um nome que ecoa uma memória religiosa de mãe (Maria, mãe de Jesus) e mulher pecadora (Maria Madalena). Ainda, não podemos nos esquecer que o nome próprio funciona como marca de autoria, configura um lugar de saber, de uma Maria que estaria autorizada a falar por outras Marias. Apagamento dos limites indecisos entre um sujeito e todos os outros, através de uma relação particularmente dinâmica entre identidade e alteridade: oscilação ambígua que distingue e separa ao mesmo tempo que integra e une.

Figura 4 - Blog "Marie accouche là".

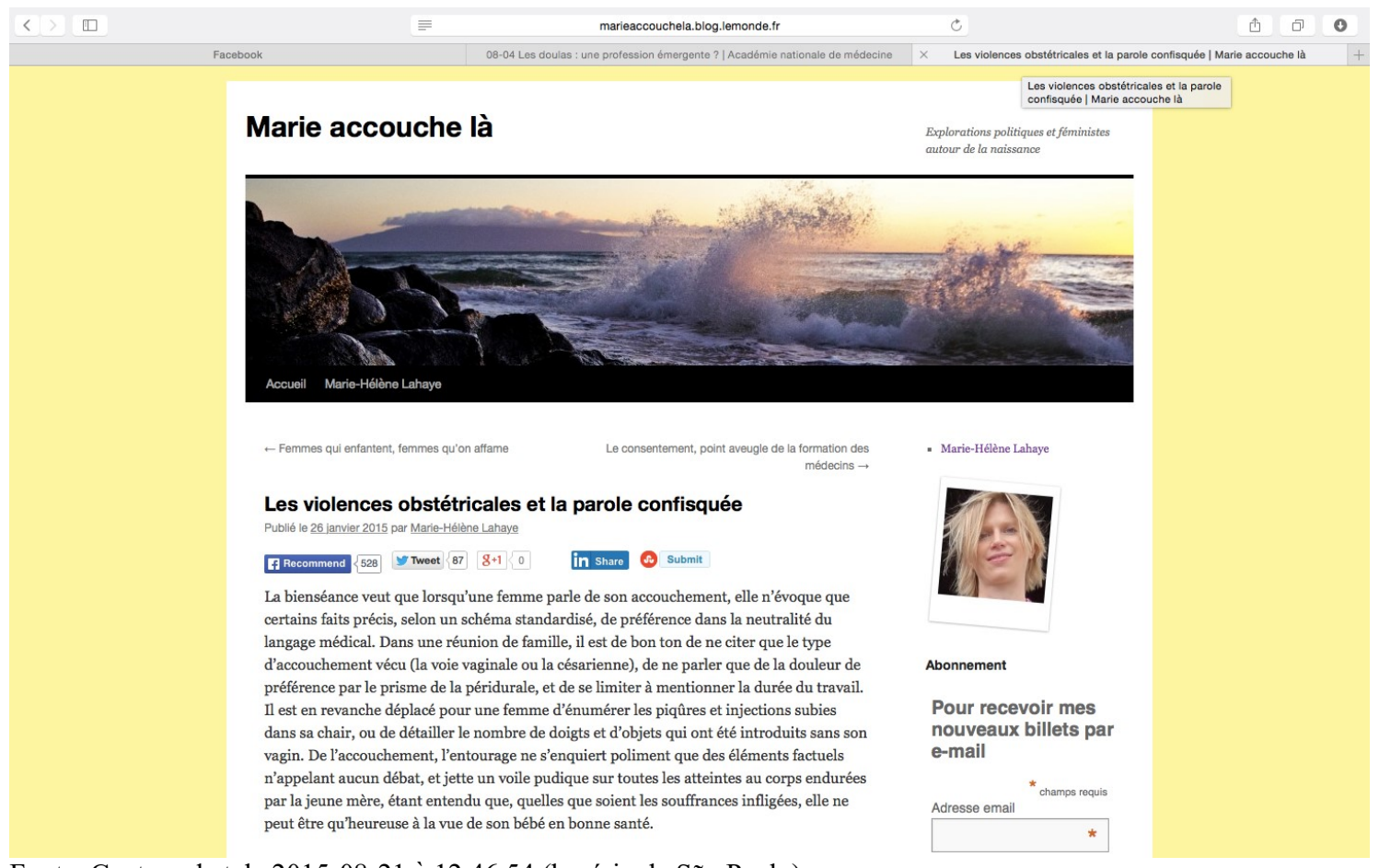

Fonte: Captura de tela 2015-08-21 à 12.46.54 (horário de São Paulo)

Mas não é apenas o funcionamento do nome próprio que demanda nosso gesto de análise. O nome do blog, "Marie accouche là", é a paráfrase de uma expressão sexista, "Marie-couche-toi-là", que embora não tenha uma expressão equivalente em português, pode ser traduzida como uma fórmula utilizada para designar uma "mulher fácil". Percebe-se que, na forma como reescreve a expressão sexista, resignificando-a, a paráfrase indica uma provocação inscrita na posição-sujeito daquele que enuncia. Segundo Butler (2004 [1997]), a linguagem da opressão não é um substituto da experiência da violência. Ela coloca em jogo sua própria forma de violência: ser insultado (to be called a name) é uma das primeiras formas de ferimento, de injúria, de "blessure". O funcionamento da interpelação a partir de uma expressão de insulto sexista pode ser considerado, assim, um processo de constituição do sujeito pela dor e pela violência. Entretanto, ao apropriar-se desta expressão sexista e resignificá-la, esse discurso produz uma posição de resistência ao sexismo e a uma memória que significa a mulher em decorrência dos estereótipos da "santa" e da "puta", desestabilizando esses estereótipos. 
No canto superior direito da página de Marie-Hélène, a descrição do blog explicita o engajamento da autora na luta feminista: "Exploration politiques et féministes autour de la naissance" (Explorações políticas e feministas em torno do nascimento): trata-se de uma posição que se nomeia como feminista, implicando-se de uma maneira particular na prática política. Na página dedicada à apresentação da bogueira, a autodescrição legitima a construção de um lugar específico na militância feminista: "Féministe aux points de vue libertaire, émancipateur et profondément ancré dans l'écologie politique" (Feminista segundo os pontos de vista libertário, emancipador e profundamente ancorado em uma ecologia política). O funcionamento da expressão "aux points de vue" é introduzir uma adjetivação ao nome "féministe", ou seja, ela sustenta os nomes que especificam e determinam o sentido de "feminista", atribuindo à autora um vínculo político com um determinado tipo de feminismo "libertário" (historicamente filiado ao anarco-feminismo), "emancipador" e ancorado em uma "ecologia política" (que explicitaria uma fíliação ao eco-feminismo). Vejamos o próximo recorte (Figura 5):

\section{Figura 5 - Página de apresentação da autora.}

\section{Marie accouche là}

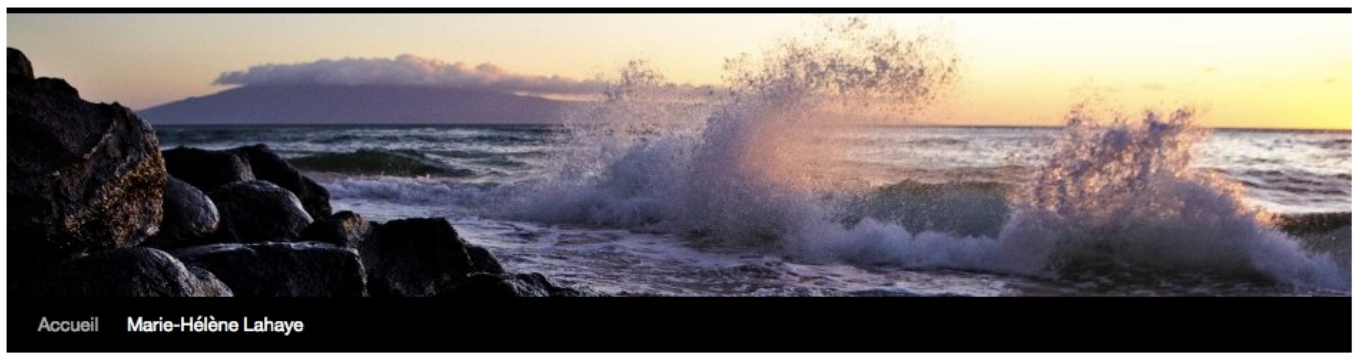

Marie-Hélène Lahaye

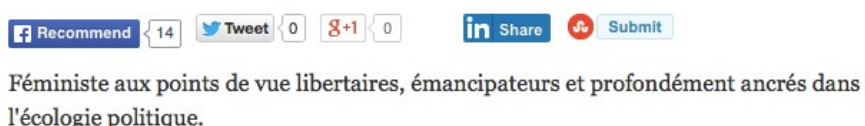
l'écologie politique.

Une émission radio dans laquelle j'interviens: « Pour une naissance respectée »

Le Journal International de Médecine a publié un article à propos de mon blog: « L'obstétrique est-elle trop paternaliste? ”

Vous trouverez sur cette page le compte-rendu d'une intervention que j'ai faite lors de la soirée organisée par le CALM sur le thème « Mon corps m'appartient... et pour accoucher? Pour un nouveau féminisme de la naissance » (voir page 9 du compte-rendu).

Une interview : « Journée de lutte contre les vioelnces faites aux femmes : interview de Marie-Hélène Lahaye »

Fonte: Captura de tela 2015-08-21 à 12.46.56 (horário de São Paulo)
- Marie-Hélène Lahaye

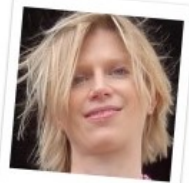

Abonnement

Pour recevoir mes nouveaux billets par e-mail

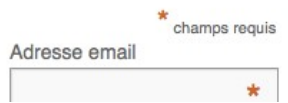

\footnotetext{
${ }^{6}$ Segundo Abbou (2011), embora a história intelectual do feminismo seja complexa e difícil de ser categorizada cronologicamente em épocas (en vagues) bem definidas, há tendências elaboradas a partir de uma epistemologia dos estudos feministas norte-americanos reconhecidamente nomeadas de acordo com suas característica (e que coabitam as diferentes "épocas" da história do feminismo). Dentre essas tendências, duas parecem aproximarem-se do ponto de vista declarado pela enunciadora: "o eco-feminismo, que articula os impactos do capitalismo sobre o meio ambiente ao patriarcado; o anarco-feminismo, que situa o feminismo em um quadro mais global de luta contra o poder" (ABBOU, 2011, p.54)
} 
Em entrevista à $\mathrm{RCF}^{7}$ presente em um dos link que figuram no recorte (Figura 5), Marie-Hélène fala em nome da plataforma digital "Pour une naissance respecté" (Por um nascimento respeitoso), espaço que enseja provocar o debate acerca da liberdade das mulheres em relação ao parto. De acordo com o manifesto lançado na plataforma, na experiência do parto altamente medicalizado a mulher é subsumida em favor de um processo de nascimento centrado na figura do médico, materializada no protocolo médico. Do ponto de vista ecológico sobre o parto, afirma Marie-Hélène, o direito à informação sobre sua própria sexualidade e sobre seu corpo é a primeira reivindicação. Entretanto, a emancipação da mulher em relação ao parto não é apenas uma questão de informação, mas de combate a um sistema de dominação - o sistema médico é masculino, majoritariamente exercido por homens e cujas normas e protocolos não contemplam a experiência feminina em relação ao corpo, explicita Marie-Hélène. Ela fala, então, do lugar de enunciação de porta-voz da plataforma, de um espaço construído institucionalmente para se ocupar dos direitos das mulheres em relação ao parto. Esse lugar institucional é perpassado, nas postagens presentes no blog, pelo discurso da ciência, especialmente pelo recurso ao uso de referências bibliográficas em seus textos como estratégia argumentativa para legitimar seu dizer. Ainda, é importante lembrar que o lugar de enunciativo a partir do qual a blogueira enuncia é perpassado pela instituição jornalística-midiática Le Monde, embora explicite sua "independência" em relação a tal espaço através de sua forma de navegação: tendo clicado no link do blog que figura no site do Le Monde, o internauta é direcionado a uma página independente, na qual o nome do jornal não aparece, salvo no endereço eletrônico do blog.

Embora não seja possível examinar outras formas de autodesignação presentes nesses e em outros blogs, consideramos a diferença em termos de produção de sentidos e de posicionamento político entre um dizer que se nomeia a partir de uma posição-sujeito fortemente vinculada a um lugar empírico de mãe (e que, portanto, constrói um sentido de maternidade atado à experiência de ser mãe), como é o caso do blog "Cientista que virou mãe" (no qual a mãe sobredetermina a cientista), e que explicitamente ancora seu lugar de fala em questões que levam em conta o "feminino"; e um dizer que se constrói discursivamente a partir de uma posição explicitamente feminista, ou seja, que assume um lugar de fala e uma responsabilidade política específica na prática militante, sem contudo ocupar uma posição relacionada à experiência da maternidade. Esses diferentes lugares de enunciação (ZOPPI-FONTANA, 2001) levam à compreensão da enunciação enquanto inscrição ideológica de um sujeito político que, ao dizer $e u$, legitima seu dizer a partir de um lugar, seja o lugar empírico de mãe-cientista (no caso do blog da pesquisadora brasileira) ou o lugar de porta-voz de uma instituição (no caso da pesquisadora Belga).

Nancy Hartsock (2003 [1983]), uma importante feminista materialista americana, elaborou o conceito de "ponto de vista" (standpoint) com o objetivo de defender e adotar um posicionamento feminista a partir das condições materiais de existência das mulheres. Seu projeto epistemológico consistia em valorizar as fontes cognitivas de mulheres, historicamente invisibilizadas e depreciadas, e transformar suas experiências em saberes.

\footnotetext{
${ }^{7}$ Disponível em <https://rcf.fr/vie-quotidienne/pour-une-naissance-respectee>. Acesso em: 10 nov. 2015.
} 
Como sublinha Maria Puig de la Bellacasa, a utilização do termo "feminista" por Hartsock marca o caráter produzido por este posicionamento, isto é, trata-se de uma posição construída a partir de uma situação sofrida e não de um ponto de vista feminino essencializado (DORLIN, 2008, p.19). Assim, além das formas de dizer-se, construídas particularmente pelas designações e autodesignações, pelo emprego dos nomes e dos adjetivos, etc. e pelos modos de leitura que oferecem aos seus interlocutores, os blog fazem uso de relatos de mulheres, em suas páginas, especialmente como forma de construir sentidos para a violência através dos testemunhos. Como veremos mais à frente, a apropriação dos relatos de violência nesses discursos faz parte do jogo da argumentação construído nesses blogs. Ao presentificar, em seus modos de formulação, a relação entre testemunho e experiência do sujeito, a apropriação (que implica necessariamente interpretação) do relato funciona de modo a marcar a evidência da verdade do enunciado: sua (re)escrita possibilita a circulação dos testemunhos em um outro tempo/espaço enunciativo no qual ele é lido/interpretado pelo(a) leitor(a).

\section{TESTEMUNHO COMO RETÓRICA DA RESISTÊNCIA}

Como nos ensinou Foucault sobre o mais "evidente e familiar" procedimento de exclusão que determina as discursividades, as interdições, "as regiões onde a grade é mais cerrada, onde os buracos negros se multiplicam, são as regiões da sexualidade e as da política" (FOUCAULT, 1996, p. 9). Afinal, é justamente no encontro dessas duas regiões que se situam as discursividades de reivindicação do corpo e do parto, pois elas permitem compreender o corpo e a sexualidade como questões inexoravelmente políticas. Essas questões são explicitadas no primeiro parágrafo da postagem do blog "Marie accouche là" (Figura 6), dedicado às interdições que administram o que pode ou deve ser dito sobre a experiência de parto, cujo efeito é o apagamento da violência cometida contra a mulher, que é subsumida em nome da saúde do bebê: "quelles que soient les souffrances infligées, elle ne peut être qu'heureuse à la vue de son bébé en bonne santé" (quaisquer que sejam os sofrimentos infringidos, ela só poderia estar feliz ao ver seu bebê em boa saúde). La "bienséance" ("conveniência" ou "decoro" na tradução que proponho) formulada logo no início do texto explicita em que medida as normas morais tracejam as fronteiras da "politesse", delineando as margens que separam palavras e comportamentos apropriados daqueles que são socialmente reprovados.

Nesta direção, a postagem (Figura 6) convoca ao debate acerca da articulação entre violência e silêncio, mostrando a tênue fronteira entre essas duas categorias, ou melhor, sugerindo que a política do silêncio funciona como mecanismo de sustentação da violência obstétrica: "Comme pour toutes les violences faites aux femmes, de puissants mécanismes de réduction au silence ouvrent pour faire taire les victimes et maintenir en place un système de domination masculine" (Como toda violência feita às mulheres, os poderosos mecanismos de redução ao silêncio trabalham para fazer silenciar as vítimas e manter no lugar um sistema de dominação masculino). A violência, nesta sequência, é explicitada como efeito da dominação masculina, mantida por mecanismos de redução ao silêncio. Segundo Orlandi (2007a), o silenciamento é produzido pela "política do silêncio" e definido pela maneira com a qual o silêncio recorta a fala, produzindo fissuras 
no dizer. A censura é esse modo particular de funcionamento do silêncio do lado da opressão, em que se proíbem certas palavras para se proibirem certos sentidos. A política do silêncio, através do mecanismo de censura, faz aparecer a falta de simetria entre os interlocutores, indica os limites das formações discursivas ao assegurar que determinados sentidos sejam necessariamente interditados: "Como, no discurso, o sujeito e o sentido se constituem ao mesmo tempo, ao se proceder desse modo se proíbe ao sujeito ocupar certos 'lugares', ou melhor, proíbem-se certas 'posições' do sujeito" (ORLANDI, 2007a, p. 76).

\section{Figura 6 - Postagem do blog "Marie accouche là". Marie accouche là}

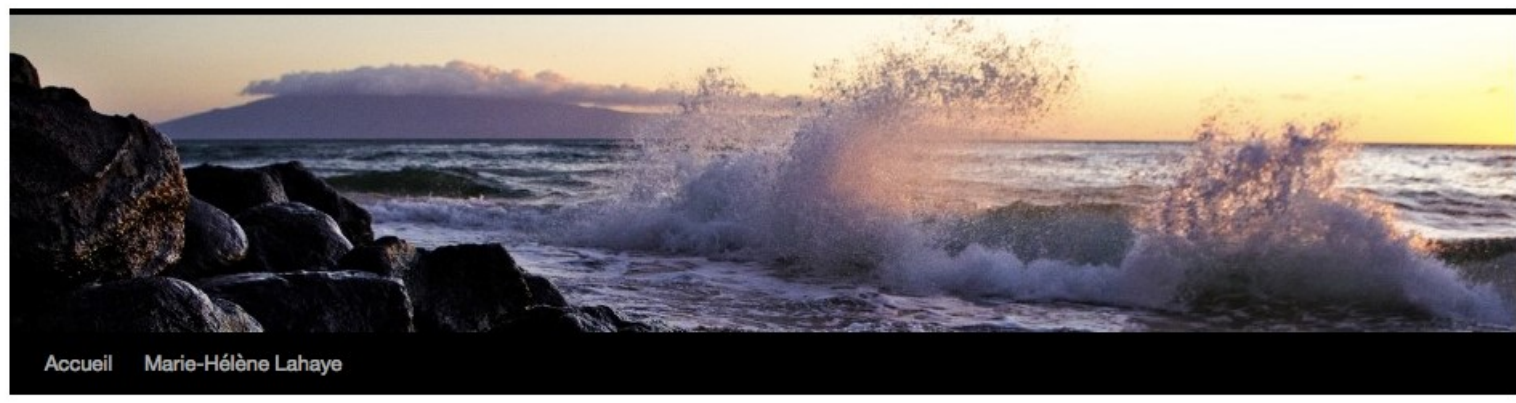

$\leftarrow$ Femmes qui enfantent, femmes qu'on affame

Le consentement, point aveugle de la formation des médecins $\rightarrow$

\section{Les violences obstétricales et la parole confisquée}

Publié le 26 janvier 2015 par Marie-Hélène Lahaye

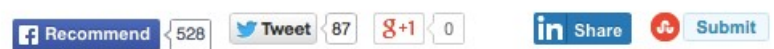

La bienséance veut que lorsqu'une femme parle de son accouchement, elle n'évoque que certains faits précis, selon un schéma standardisé, de préférence dans la neutralité du langage médical. Dans une réunion de famille, il est de bon ton de ne citer que le type d'accouchement vécu (la voie vaginale ou la césarienne), de ne parler que de la douleur de préférence par le prisme de la péridurale, et de se limiter à mentionner la durée du travail. Il est en revanche déplacé pour une femme d'énumérer les piqûres et injections subies dans sa chair, ou de détailler le nombre de doigts et d'objets qui ont été introduits sans son vagin. De l'accouchement, l'entourage ne s'enquiert poliment que des éléments factuels n'appelant aucun débat, et jette un voile pudique sur toutes les atteintes au corps endurées par la jeune mère, étant entendu que, quelles que soient les souffrances infligées, elle ne peut être qu'heureuse à la vue de son bébé en bonne santé.
- Marie-Hélène Lahaye

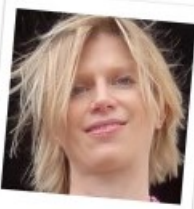

Abonnement

Pour recevoir mes nouveaux billets par e-mail

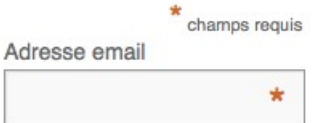

Fonte: Captura de tela 2015-08-26 à 10.18.56 (horário de São Paulo)

Assim, estes discursos de militância oferecem um lugar de simbolização da dor e das demandas de sujeitos historicamente silenciados, embora tragam em seu funcionamento outros silenciamentos (de mulheres periféricas negras, indígenas, imigrantes, etc., mulheres cujos lugares de enunciação permanecem interditados, à margem desses discursos). Nesta direção, a tecnologia da escrita, compreendida como fenômeno urbano ligado as redes sociais digitais, possibilitam um movimento no percurso desses sujeitos em direção à denuncia da dor e da opressão.

Como disse Barthes (2004, p. 219), a escrita constitui um meio de nos precaver contra o risco de um intervalo mortal, no qual um sujeito em "estado de queda infinita" 
pode se agarrar a algo e, assim, sobreviver. É o que o próximo recorte (Figura 7) nos permite vislumbrar, a aptidão da escrita para resolver um trauma, o que possibilita teorizála a partir de uma "função tranquilizadora" (WIEVIORKA, 2013 [1998], p. 31), um tipo de solução simbólica que enseja suturar a ferida aberta pelo trauma, produzindo o testemunho como marca, cicatriz da violência.

Escrever é uma relação particular com o silêncio. A escrita permite o distanciamento da vida cotidiana, a suspensão dos acontecimentos. Ela permite que se signifique em silêncio. Assim, há auto-referência sem que haja intervenções da situação ordinária (a censura) de vida: o autor escreve para significar (a) ele mesmo. É um modo de reação ao automatismo do cotidiano, marcado pela censura. Com o distanciamento estabelecido pela escrita, os movimentos identitários podem fluir, podem ser trabalhados pelos sentidos (ORLANDI, 2007a, p. 83).

\section{Figura 7 - Recorte da postagem "Les violences obstétricales et la parole confisquée" divulgada no blog "Marie accouche là".}

Si le viol est de plus en plus dénoncé, il n'en est pas encore de même pour les violences obstétricales, ce qui rend ces dernières encore plus difficilement audibles et donc dicibles. Pourtant, l'ampleur et la variété des atteintes aux droits humains dans les maternités ne pourront être prises en compte que si les mères se mettent à parler de leur accouchement, $\mathrm{y}$ compris en transgressant les règles de bienséance et de pudeur qui les emprisonnent dans le silence. Les témoignages sont dès lors capitaux.

Je reçois régulièrement des courriers de femmes me détaillant les douloureuses expériences qu'elles ont vécues en mettant leur enfant au monde. J'ai donc décidé d'en publier un avec l'autorisation de l'auteure. Voici celui d'Alice qui s'est vue imposer une césarienne contre sa volonté, puis qui s'est heurtée à l'incompréhension de son entourage. Elle a malgré tout persévéré en écrivant ce texte qu'elle a lu à sa famille et à ses amis.

"On a décidé pour moi. Au cas où l'accouchement se passerait mal. On allait me couper le ventre. Et l'utérus. La société a décidé pour moi. Alors au milieu de mon accouchement, alors que j'étais en train de donner vie à ma petite fille, on m'a droguée, on m'a rasée, on m'a piquée, on m'a coupée et en cinq minutes ma fille était née.

Fonte: Captura de tela 2015-08-26 à 14.44.09 (horário de São Paulo)

Podemos considerar, então, a escrita como um sintoma justamente porque ela é uma prática pela qual o sujeito abandona o silêncio ao reivindicar, pelo gesto que ela enseja, algo da ordem de sua subjetividade. Ela materializa uma demanda de reivindicação do corpo do sujeito, ou seja, textualiza a reclamação do direito de dispor de seu útero e de viver sua experiência de parto "livremente". Consideramos, então, o testemunho como escritura de resistência na medida em que ele rompe com uma suposta "normalidade" da prática médica, construindo um lugar de oposição e denúncia da violência contida em tais práticas. Segundo Annette Wieviorka (2013 [1998]), os testemunhos, sobretudo quando eles se encontram 
integrados a um movimento de massa, não exprimem apenas a experiência individual, mas os discursos de uma sociedade no momento em que a testemunha conta sua história. Ele expõe, em princípio, a singularidade de que cada experiência narrada, embora fale também dos jogos políticos e ideológicos, contribuindo para a construção de uma memória coletiva que privilegia o ponto de vista do oprimido. Tal prática discursiva de escritura de si e do outro permite "narrar um outra história": elas tornam públicas e "transformam politicamente em público abusos que foram vividos como privados e ocultados pelos sujeitos individuais traumatizados" (FELMAN, 2014, p. 27).

\begin{abstract}
Testemunhos de naturezas diferentes uns dos outros, produzidos a distância diversas do acontecimento, inscritos em suportes múltiplos: manuscritos ou livros, jornais, cassetes, vídeos... Algumas provenientes de um movimento espontâneo, de uma necessidade interior. Outros respondem a demandas de origens diversas. Demandas ligadas a necessidade de justiça (WIEVIORKA, 2013 [1998], p. 12-13) ${ }^{8}$
\end{abstract}

Como apresenta Wieviorka, os testemunhos podem ser produzidos por uma necessidade interior, e inscritos em diferentes suportes. Eles também podem responder a demandas de origens diversas, relacionadas ao desejo de justiça e reparação moral. Desta maneira, a análise de testemunhos oferece outros caminhos nos quais é possível problematizar uma "ética linguageira" (PAVEAU, 2015) que sustenta esses discursos e que leva a considerar a responsabilidade do sujeito face a sua própria fala e à fala do outro. A compreensão da eficácia social do testemunho como forma de condenação do agressor exige, assim, um trabalho sobre o funcionamento do discurso relatado.

\title{
5 CONSIDERAÇÕES FINAIS
}

\begin{abstract}
Não é assim tão óbvio que a escrita sirva para comunicar; é por um abuso de nosso etnocentrismo que atribuímos à escrita funções puramente práticas de contabilidade, comunicação e registro, e que censuramos o simbolismo que move o signo escrito. (BARTHES, 2004, p.182).
\end{abstract}

Se, junto a Pêcheux (2010 [1975], p. 25), levamos a sério a questão da divisão discursiva por detrás da unidade da língua, compreendemos que "divulgar" e "informar" são práticas que devem ser consideradas no interior da unidade dividida e contraditória da comunicação/não comunicação, ou seja, de que, sob a aparência de uma comunicação sem equívocos reside a não comunicação: a contradição e o equívoco são, pois, elementos fundantes das discursividades. As práticas discursivas examinadas neste artigo se sustentam, portanto, na evidência da comunicação que, como a propaganda, "se faz com imagens e palavras, sentimentos, ideias e gestos” (PÊCHEUX, 2011 [1979], p.74). Elas produzem "novos tipos de performativos interpelando o sujeito a partir de seu próprio narcisismo", reorganizando nossa relação com o nosso corpo. "A gestão política da sexualidade, no cotidiano da publicidade, da propaganda e da produção cultural, constitui um ponto privilegiado desta reorganização." (2011 [1979], p. 88), diz Pêcheux.

\footnotetext{
8. "Témoignages de nature différente les uns des autres, produit à diverses distances de l'événement, inscrits sur des supports multiples: manuscrits ou livres, journaux, bandes magnétiques, cassettes vidéo... Certains proviennent d'un mouvement spontané, d'une nécessité intérieure. D'autres répondent à des demandes d'origines diverses. Demandes liées au besoin de la justice, d'abord". A tradução livre é minha.
} 
A língua de vento sustenta a política do performativo, segundo Pêcheux, e nos coloca "a questão de saber quem está 'no direito' de produzir os enunciados performativos" (PÊCHEUX, 2011 [1979], p. 89), isto é, quem está autorizado, nestes discursos militantes, a falar em nome das outras mulheres (de todas as mulheres?), produzindo uma política imaginária na qual prevalece a ordem do parecer em que gestos e declarações substituem as práticas. A militância no ciberespaço, assim, pelo modo com que ela funciona, se inscreveria na aparência-falsa da política imaginária, tornando-se um simulacro do real? Ou ela é capaz de intervir no real, produzindo uma ruptura nas discursividades acerca do parto e do nascimento em nossa formação social?

Ao observar o funcionamento da argumentação, nesses discursos de militância, constatamos que o testemunho tem papel capital na produção de um efeito de verdade que sustenta, por assim dizer, a própria prática de militância. No espaço interpretativo do blog, a produção de uma escrita de si (na qual o pessoal e o institucional se atravessam) consiste em um gesto de autoria cuja materialidade constitui o sujeito e a situação, pelo funcionamento da memória. Dito de outro modo, consideramos os blogs como lugares de autoria que incorporam um corpo outro, uma dor outra, a partir de uma posição sujeito, dando consistência à prática militante como prática de denúncia. Nesta direção, é possível considerar os blogs como "espaços narrativos" (ORLANDI, 2015), ou seja, espaços de interpretação que ensejam formas outras de dizer o parto e o nascimento. "Espaço político, logo, espaço da divisão, da dissimetria, do resto", acrescentaria Eni Orlandi (2015, p. 22). Lugares de textualização da violência, pela narratividade da dor, cujo funcionamento produz um gesto de resistência, pela denúncia. Gesto que intervém na história ao produzir outros modos de narrar o parto, desorganizando o discurso médico estabilizado que governa e administra nossos corpos. Testemunho de um corpo de re(existe).

\section{REFERÊNCIAS}

ABBOU, J. L'antisexisme linguistique dans les brochures libertaires: pratiques d'écriture et métadiscours. Linguistics. Université de Provence - Aix-Marseille I, 2011.

BARTHES, R. Inéditos. Vol.1 - Teoria. Trad. Ivone Castilho Benedetti. São Paulo: Martins Fontes, 2004.

BUTLER, J. [1997]. Le pouvoir des mots. Discours de haine et politique du performatif. Paris: Édition Amsterdam, 2004.

DIAS, C. Sujeito, sociedade e tecnologia: a discursividade da rede (de sentidos). São Paulo - SP: Hucitec, 2012.

DORLIN, E. Sexe, genre et sexualités. Paris: Puf, 2008.

FELMAN, S. O inconsciente jurídico. Julgamentos e traumas no século XX. Trad. Ariani Bueno Sudatti. São Paulo: EDIPRO, 2014.

FOUCAULT, M. A ordem do discurso. São Paulo: Loyola, 1996.

GUILHAUMOU, J. Le nom propre en discours. In: Mots. Les langages du politique [En ligne], 92 | 2010, mis en ligne le 4 mai 2012. Disponível em: <http://mots.revues.org/19600> Acesso em: 19 out. 2015.

GUIMARÃES, E. Os limites do sentido. Campinas: Pontes, 1995.

HARTSOCK, N. [1983]. The feminist standpoint: Developing the ground for a specifically feminist historical materialim. In: HARDING, S. (Org.). The Feminist Standpoint Theory Reader. New York: Routledge, 2003.

INDURSKY, F. A fala dos quartéis e as outras vozes. Campinas: Editora da Unicamp, 1997. 
MITTMANN, S. Alguns apontamentos sobre militância digital. In: GRIGOLETTO, E.; NARDI, F. S. de; SCHONS, C. R. (Org.). Discursos em rede: práticas de (re)produção, movimentos de resistência e constituição de subjetividades no ciberespaço. Recife: Ed. Universitária, 2011. p. 119-139.

ORLANDI, E. P. Discurso e argumentação: um Observatório do Político. Fórum Lingüístico, Florianópolis, n. 1, p. 73-81, jul.-dez. 1998. $2007 \mathrm{a}$.

[1992] As formas do silêncio: no movimento dos sentidos. Campinas: Editora da Unicamp,

[1996] Interpretação. Autoria, leitura e efeitos do trabalho simbólico. Campinas: Pontes, 2007b. Análise de discurso. In: ORLANDI, E. P.; LAGAZZI-RODRIGUES, S. (Org.). Introdução às Ciências da Linguagem - Discurso e textualidade. Campinas: Pontes, 2010. p. 11-31.

. Na trilha: teoria, autoria, reescrita. In: INDURSKY, F.; FERREIRA, M. C. L.; MITTMANN, S. (Org.) Análise do discurso: dos fundamentos aos desdobramentos. 30 anos de Michel Pêcheux. Campinas: Mercado das Letras, 2015.

PAYER, M. O. Escrever, (d)enunciar a verdade, sugerir sentidos. In: MARIANI, B. (Org.) A escrita e os escritos: reflexões em análise de discurso e psicanálise. São Carlos: Claraluz, 2006.

PAVEAU, M.-A. Linguagem e moral. Uma ética das virtudes discursivas. Campinas: Editora da Unicamp, 2015.

.Technodiscursivités natives sur Twitter. Une écologie du discours numérique. In: LIÉNARD, F. Culture, identity and digital writing, Epistémè 9, Revue Internationale de Sciences Humaines et Sociales Appliquées. Séoul: Université Korea, Center for Applied Cultural Studies, p. 139-176, 2013.

Présentation. Itinéraires [En ligne], 2014-1 | 2015, mis en ligne le 06 février 2015. Disponível em :<http://itineraires.revues.org/2312>. Acesso em: 19 out. 2015.

PÊCHEUX, M. [1969]. Análise Automática do Discurso (AAD-69). In: GADET, F.; HAK, T. Por uma análise automática do discurso: uma introdução à obra de Michel Pêcheux. Tradução de Bethania Mariani et al. Campinas: Unicamp, 1990a. p. 61-161.

[1982] Delimitações, inversões, deslocamentos. Trad. José Horta Nunes. Cadernos de Estudos Linguísticos, Campinas, v. 19, p. 7-24, jul./dez. 1990b.

[1982]. Ler o arquivo hoje. Trad. Maria das Graças Lopes Morin do Amaral. In: ORLANDI, E. P. (Org.). Gestos de leitura: da história no discurso. Campinas, SP: Editora da Unicamp, 1994. p. 55-66.

[1975] Semântica e Discurso - uma crítica à afirmação do óbvio. Campinas: Editora da Unicamp, 2010.

[1979]. Foi "propaganda" mesmo que você disse? In: Análise de Discurso: Michel Pêcheux. Textos escolhidos por Eni Puccinelli Orlandi. Campinas : Pontes, 2011. p. 73-92.

WIEVIORKA, A. [1998]. L'ère du témoin. Paris: Pluriel, 2013.

ZOPPI-FONTANA, M. Lugares de enunciação e discurso. CONGRESSO INTERNACIONAL DA ABRALIN, 2., Fortaleza, Universidade Federal do Ceará, 2001.

E o nome que faz fronteira. In: INDURSKY, F.; FERREIRA, M. C. L. (Org.) Os múltiplos territórios da Análise do Discurso. Porto Alegre: UFRGS, 1999. (Coleção Ensaios do CPG-Letras).

\title{
Recebido em: 04/12/15. Aprovado em: 25/05/16.
}

Title: Feminist activism on the internet: how argumentation in discourses about violation during childbirth works

\begin{abstract}
Author: Aline Fernandes de Azevedo Bocchi
Abstract: In this study, we examine the discursive and argumentative categories of activist feminist discourses, prioritizing the lexical-semantic meta-discourses which textualize medical violation against women during childbirth, in other words, linguistic formulations that materialize the way in which power relations cross over and comprise these discourses. We question, therefore, evidence ideologically constructed concerning the categories of violation and activism by using a discursive approach, which enables us to analyze and problematize discourses designated as feminist and textualized in digital materiality. Our interest focuses on how naming and testimonies in activist blogs work, which are considered places of interpreting and reformulating experiences of violation in digital space.
\end{abstract}

Keywords: Discourse analysis. Feminism. Childbirth. Violation.

BOCCHI, Aline Fernandes de Azevedo. A militância feminista na Web: o funcionamento da argumentação em discursos sobre a violência no parto. Linguagem em (Dis)curso - LemD, Tubarão, SC, v. 16, n. 2, p. 309-328 maio/ago. 2016. 
Título: La militancia feminista en la web: el funcionamiento de la argumentación en discursos sobre la violencia en el parto

Autor: Aline Fernandes de Azevedo Bocchi

Resumen: En este estudio son examinadas las categorías discursivas y argumentativas de los discursos feministas militantes, priorizando los meta discursos léxico-semánticos que textualizan la violencia médica contra la mujer durante el parto, es decir, las formulaciones lingüísticas que materializan el modo como las relaciones de poder atraviesan y constituyen eses discursos. De esta manera se questionan las evidencias ideológicamente construidas acerca de las categorías de violencia y militancia por medio de un abordaje discursivo (PÊCHEUX, 1969; 1975; 1983) que permite el análisis y problematizaión de discursos nombrados feministas y textualizados en la materialidad significante digital. El interés está dirigido principalmente para el funcionamiento de los significados y de los testimonios en blogs militantes considerados lugares de interpretación y reformulación de la experiencia de la violencia en el espacio digital.

Palabras-clave: Análisis del discurso. Feminismo. Parto. Violencia.

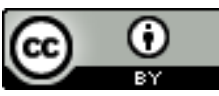

Este texto está licenciado com uma Licença Creative Commons Atribuição 4.0 Internacional. 